Scientific misconduct

Many people might conclude that scientific misconduct is a problem confined to the United States. It is not. At least five cases are documented in Britain, and my own (incomplete and non-systematic) studies have uncovered at least another 40 unreported ones. In Australia another five are on the record, while the current allegations against Dr William McBride, who is accused of falsifying data in a study of Debendox, show how difficult it is to conduct investigations in a non-academic setting. So the September Washington workshop on responsible medical research has implications far wider than might have been thought.

The original incentive was obviously to see what lessons could be learnt from the classic cases of misconduct in the United States and the analyses by commentators such as Stewart and Feder (BMF, 6 February, p 376). But in the past few months three other developments made the three days spent by the American medical good and the great particularly timely. Guidelines issued by Harvard University in April limiting the number of papers that can be cited for academic promotion seemed one answer to a

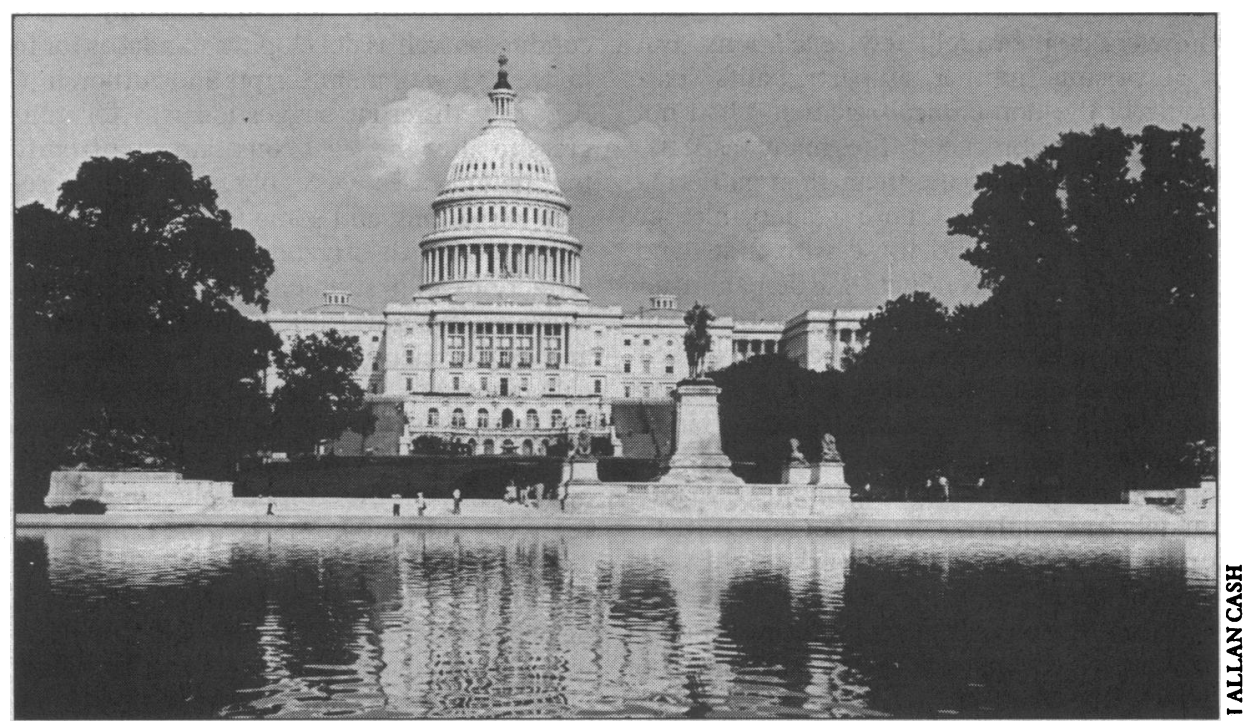

Scientific research: time to put the house in order

major cause of sloppy science: excessive publication. The calls in the summer in the American congress for official scrutiny of scientific research had threatened the fragile creative process, implying that the government would act unless medical science rapidly put its house in order. And the extreme sanction for one fraudster was announced in the week of the workshop: the first criminal conviction, of Stephen Breuning, whose faked results had altered clinical policy on drug treatment for mentally handicapped children. A final frisson was provided by the rumours circulating during the meeting that yet more cases of scientific misconduct were about to be reported.

The 100 workshop members spent much of their time in panels discussing standards:

\section{Scrutinising research ethics committees}

For the first time since 1975 the government is turning its attention to research ethics committees. A recent seminar organised by the West Birmingham Community Health Council produced points the Department of Health might wish to consider.

Clear rules for conducting research are urgently needed-existing guidelines in many areas are still hopelessly vague. Who sits on committees and how they operate need sorting out. Though the committee in one health authority may meet fortnightly, in the next it may never have met, conducting all its affairs by post. No one knows whether each district has its own ethics committee.

Originally committees were set up by institutions, but the development of health authorities brought a change in their focus of accountability (although not a consistent change-in the mid1980s the Institute of Medical Ethics identified eight different organisational and administrative frameworks within which ethics committees existed). It is time that the constitutional framework of ethical committees was clarified: accountability through the health authority would seem the best model.

Underlying the confusion are two main problems. The first is that neither ethics committees nor their decisions have any legal status. In practice ethical committees may exercise some control, but this needs to be put on a firmer footing, and there should be a statutory requirement for all research to be submitted to an ethics committee.

The second problem is that no one is sure for which projects the committees should be responsible and what "being responsible" means. Comments reported in the June issue of the Bulletin of the Institute of Medical Ethics about how members of German ethics committees saw themselves-"undecided whether they serve as a facility of control or simply as consultants to others who are liable for any decisions made"-were echoed by participants at the seminar in Birmingham.

With so many new treatments trailing complicated ethical problems it is important that some of the uncertainties are removed soon. One way of doing this would be to set up a national ethics committee-something like the Voluntary Licensing Authority (set up to oversee in vitro fertilisation)-for work with an ethical content in topics other than reproduction.

This is not to belittle the work of local committees: local circumstances may have an important bearing on the ethical aspects of a protocol and must still be taken into account. Nevertheless, it would clearly be desirable for local decisions to be made within a framework that was reasonably coherent. Experiences of lay members from the 19 different ethical committees who attended the Birmingham seminar confirmed this.

The seminar also suggested finding more systematic ways of promoting elements of good practice: most people left the seminar with ideas for improving the conduct of their own ethical committees that were already routine practice elsewhere. - T MARSHALL, lecturer in social medicine, and PETER MOODIE, lecturer, faculty of law, Birmingham 
of laboratory and clinical research, supervision, training, career advancement, and publishing practices. Wisely, the discussions overlapped, but their themes came out in a plenary session held at the end of the first day so that each panel could then go back and avoid too much duplication. The final reports were discussed at length in a concluding plenary session.

To anyone who has followed the misconduct-fraud saga over the past eight years the workshop brought few revelations. But a surprising number of participants (particularly the non-clinical scientists) had not previously appreciated the many aspects. How better to educate them than gathering them together with those responsible for setting standards and those with first hand experience of misconduct? Participant after participant cited the aetiological theme of sloppy science, with its spectrum of self delusion through trimming and cooking to the frank forgery of results. A major factor had been inadequate supervision by the principal investigators, who might be inadequately trained themselves. Incomplete institutional peer review of the work might then allow it to be published. Finally, there was "gift" or "honorary" authorship: putting on the article the names of those who knew too little about the work to be able to justify or monitor it.

Given these factors the workshop's recom- mendations followed naturally. Though no studies of prevalence had been done, frank fraud was thought to be rare. No system could stop it, but raising standards of training and supervision would prevent a lot of sloppy science. Both investigators and mentors needed help, particularly about research ideals (a booklet was one suggestion), and there should be much more internal peer review. Institutions should be explicit about their mechanism for investigating misconduct as well as developing standards for in house review of manuscripts and authorship. A totally different suggestion was for congress to alter the legal constraints: currently too many cases were obscured by secret plea bargaining and some journals had been threatened with litigation if they published retractions of fraudulent work. Otherwise, however, the government should stay away and let the scientific community deal with its own deviants.

The workshop, on 6-8 September, was organised by the Institute of Medicine's committee on the responsible conduct of research, being sponsored by the Committee on Science, Engineering, and Public Policy (a joint unit of the National Academy of Sciences, the National Academy of Engineering, and the Institute of Medicine). Its report on scientific responsibility and quality assurance in the health sciences should be published early in 1989. - STEPHEN LOCK

\section{Dying for a job}

Major accident rates on the Youth Training Scheme have more than doubled since 1984, the first full year of the scheme's operation. Two trainees have died and 148 suffered major injuries in the first quarter of this year. Accident rates now exceed those reported in traditionally hazardous industries, such as shipbuilding.

According to the Unemployment Unit, which has compiled the figures from Training Commission reports, especially dangerous environments do not explain trainees' high accident rates: fewer than $14 \%$ work in the manufacturing and industrial sector and only $3 \%$ in construction.

The unit attributes the high rates to inadequate supervision of trainees and a failure to make them aware of standard safety precautions in the workplace. This responsibility lies with employers and managing agents, who, once granted government approval, are largely self policing. Officers from the Training Commission inspect infrequently. While accident rates have been increasing the number of schemes closed for safety reasons has fallen (from 44 in the first quarter of 1987 to 20 in the first quarter of 1988). Applications to the scheme that were refused on grounds of safety fell in 1987.

The Department of Employment now offers a place on the scheme to every school leaver under 18. In a move to reduce the number of "voluntarily unemployed" the government abolished income support to 16 and 17 year olds on 12 September this year.

\section{Listeriosis}

Listeriosis is increasing in western Europe and North America. Laboratory reports in England and Wales to the Communicable Disease Surveillance Centre rose from around 100 each year two years ago to over 250 in 1987. Some of this increase is because of greater awareness of the disease, increased detection in the laboratory, and better reporting, but it also probably represents a real increase in incidence.

Most of the reported cases have been of bacteraemia and meningitis in elderly people, those whose immune system is compromised, pregnant women, and newborn infants; but some cases have occurred in previously healthy young adults. The case fatality rate is between $25 \%$ and $30 \%$, but listeriosis is registered as the underlying cause of death in only about half of such cases.

Most cases are sporadic and apparently epidemiologically unrelated, but recently several foodborne outbreaks have been reported that were associated with raw milk and unpasteurised cheese. In one milkborne outbreak in the United States the milk had apparently been adequately pasteurised. In 1987 an outbreak of 40 cases in Switzerland was traced to Swiss Vacherin cheese, but epidemiological investigations in England and Wales failed to detect any cases associated with this product.

Only two cases of foodborne listeriosis have been recorded in this country, both associated with unpasteurised cheese. The first, in January 1986, was associated with soft cheese imported from France, and the second, in March 1987, was caused by locally produced goats' milk cheese.

A notable outbreak occurred in Canada in 1981 in which the vehicle of infection was shown to be raw cabbage in a coleslaw salad. The cabbages had come from a farm where they had been fertilised with manure from a flock of sheep that was later shown to be infected. Listeriosis in sheep in England and Wales is reported to have increased, but there is no evidence of any association between infection in sheep and foodborne disease in humans.

The epidemiology of human listeriosis seems to be changing. The incidence is increasing, and foodborne infection is becoming more common. These changes may be associated with the increased use of prolonged refrigeration of perishable foods that are consumed raw, particularly milk, cheese, and vegetables.

Listeria monocytogenes is widespread in animals, and will inevitably be present in small amounts in raw animal and vegetable products. It grows at the temperatures of refrigeration $\left(4^{\circ} \mathrm{C}\right)$ : indeed, "cold enrichment" is used to culture the organism in the laboratory. A small inoculum on foods may proliferate during prolonged refrigeration, outgrowing competing organisms and producing sufficient numbers to cause infection and illness in susceptible people.

Detailed epidemiological inquiries are needed to confirm this hypothesis. Microbiologists should report cases in the usual 
way to the Communicable Disease Surveillance Centre, 61 Colindale Avenue, London NW9 5EQ, or to the Communicable Diseases (Scotland) Unit, Ruchill Hospital, Glasgow G20 9NB, so that these inquiries may be coordinated nationally. $-\mathrm{N}$ S GALBRAITH, Blackheath, London

\section{Immunising children in hospital}

With the arrival next week of MMR vaccine against mumps, measles, and rubella Britain is about to try hard to boost rates of immunisation. One extra way of increasing the rates would be to respond to children seen in hospital who are found to be not fully immunised.

A recent editorial in the American fournal of Diseases in Childhood strongly urges this policy. Vincent Fulginiti, the editor of the journal, argues that it would be simple to introduce a policy that all children admitted to hospitals be screened for their immunisation state and any deficiencies be corrected

\section{How smart cards work}

A smart card looks like just another credit card. What makes it different, however, is that embedded within it is a single chip computer. This may be accessed by external contacts and stored information displayed or added to.

Two of the card's features make it particularly suitable for storing medical records. The first is that the chip's memory can be partitioned to provide different levels of access to the stored data. The second is that the card's microprocessor (and not the external terminal) determines authorisation of access.

In practice this means that before the card supplies any information users, who could be doctors, dentists, or pharmacists, have to key in their own identification number, specifying their level of access. Using their own (secret) numbers patients will have access to all the data stored on their cards - in compliance with the Data Protection Act.

As adapted for use with patients smart cards are not meant to replace the main

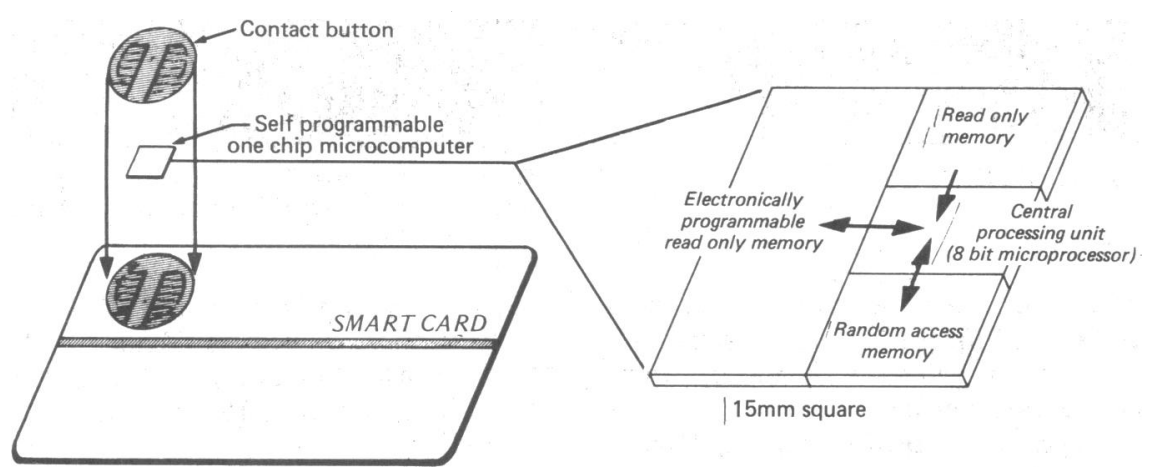

\section{Effect of vaccination in the United States}

\section{Cases per 100000 population}
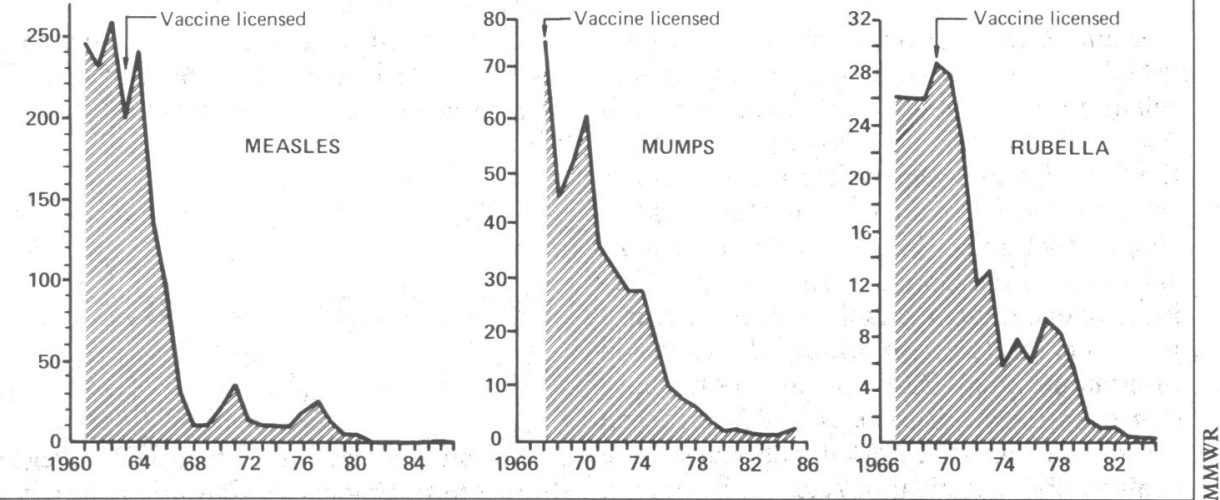

there and then, or planned after discharge. The idea is simple; its application is difficult. Success would depend on informed and committed medical and nursing hospital staff and a system that records the information and activates the necessary follow up. Nevertheless, though difficult, both developments are not impossible. Enthusiastic staff cannot succeed without the system, and the system would not succeed without, at the very least, the compliance of the staff.

medical records held in doctors' surgeries and hospitals. Instead, they will provide a portable version of them.

The cards' main advantage is expected to be providing a secure and efficient link between different members of the health team. For example, inpatient notes can be added to the card, allowing general practitioners access to them immediately on a patient's discharge; patients' vaccination histories could be stored on the card; consent for providing organs for transplantation could be recorded.

The card could also provide pharmacists with restricted access to past and present drugs and a summary of previous clinical problems and drug reactions. Similar information would help dentists too.

A two year trial of smart cards is due to begin in October in Devon. Some 8500 Care Cards, as they are to be called, will be issued to selected patients and facilities provided for accessing them. Supplied in this quantity (in this case by Honeywell Bull) the cost of each card would be between $£ 3$ and $£ 4$.

If a hospital service is to be engaged in reinforcing the immunisation programme within the community the response should be the same whether a child is admitted to the wards or attends outpatient or accident and emergency departments. In accident and emergency departments immunisation state often needs to be known with respect to the tetanus component of the triple vaccine. The numbers of children attending accident and emergency and outpatient departments are considerable. The departments are thus an effective net and may well identify many of the children who have missed out on their immunisation schedule because of recurrent illnesses or lack of parental awareness.

Our practice in Nottingham is for the liaison health visitor to inform the community of children identified in the accident and emergency department as needing immunisation. There is no reason why all the children attending or admitted to hospital should not be similarly identified. When their infants are ill may well be the best time to advise some parents of what protection is available against other illnesses.

A system would be needed if the child was to be immunised there and then. For this the hospital would need access to up to date records as many parents cannot recall, or recall accurately, the immunisation state of their children. Only when such information is available would it be appropriate to offer immunisation in hospital. A record held by parents would help, which could be a smart card (see box), but whether the parents of unprotected children would always carry such a record would have to be determined. Informing the family doctor and community services and properly recording that a vaccine has been given would also be essential.

With the computerisation of records, the new issue of guidance from the Department of Health and Social Security, and the introduction of measles, mumps, and rubella vaccine now would seem to be an appropriate time for those concerned with hospital services for children, particularly paediatricians, to consider what can be done within the hospital service to improve the rate of uptake of vaccination within their community, specifically what their response should be when a junior doctor reports that a child has not been immunised.-DAvID HULL, professor of child health, University Hospital, Nottingham NG7 2UH 


\section{Boosting European science}

Scientific Europe, a book that is to be published next year in at least five languages to celebrate the strengths of western European science, is the first scheduled product from the Foundation Scientific Europe, which was launched earlier this month at Maastricht in The Netherlands. Also on the foundation's agenda are a multilingual magazine popularising science and technology from a European perspective; multilingual television programmes; a Euroscience book club; efforts to inject characteristically European components into the work of national science centres; and a festival of science, beginning in 1992 and to be held in a different city every five years. Plans are also afoot to foster developing a European Association for the Advancement of Science in close collaboration with national organisations such as the British Association for the Advancement of Science.

The foundation is the brainchild of Dutchman Theo Martens, whose company publishes Natuur $\mathcal{E}$ Techniek and popular science books. He says that Scientific Europe will "emphasise that much of the world's most innovative science originates not in America or Japan but here in Europe." Both the book and the foundation were conceived "to remind Europeans - whether as shoppers or voters, students or investors, researchers or entrepreneurs - of our sometimes overshadowed achievements and our enormous potential for the future."

The immediate priority for Foundation Scientific Europe is to raise seven million European currency units for its first five years of operations. The Dutch Ministry of Education and Science has agreed to provide some financial support provided that the foundation advances the launch of its magazine, presently scheduled for 1992 .

The foundation may be contacted at PO Box 415, 6200 AK Maastricht, The Netherlands. - BERNARD DIXON

\section{Blood, sweat, and tiers}

At the annual meeting of the Royal College of Surgeons of England in Cambridge last week surgeons voted to reject plans to add a third tier to their fellowship examination. The president and secretary of the Association of Surgeons in Training led the opposition to the additional examination.

This follows several years of discussions among the surgical colleges of Britain and Ireland about restructuring higher surgical training. At one stage there were plans to collapse the two parts of the current fellowship examination into one and to create a new second examination, which would serve as a specialist qualification. But the range of material that the candidate for the new first part would have to cover was considered too daunting - hence the plans to add a third tier instead.

This third tier was criticised because it would mean surgeons in some cases sitting exams 12-15 years after qualifying. Another criticism was that it would not be rigorous enough to count as a worthwhile specialist qualification: it is a widely held belief that after so many years of training most entrants would get through "on the nod."

The vote at the meeting does not solve the problem for those specialists who believe that standards of training in their branch of surgery are falling behind what exists elsewhere. The solution for which the ophthalmologists and otolaryngologists have opted is to follow the first part of the fellowship with their own specialist examination. Some neurosurgeons, paediatric surgeons, plastic surgeons, and thoracic surgeons would like to follow suit. - TONY DELAMOTHE

\section{Postal dispute}

Although the postal dispute in the United Kingdom is now over, it will take the Post Office two to three weeks to clear the backlog so delays are likely for a week or two. To minimise these delays a group of publishers producing weekly journals, including the $B M \mathcal{H}$, has arranged to have copies of their journals delivered to all general practices and to 1162 hospitals in the United Kingdom. Extra copies have also been sent to BMA regional offices. The job advertisements published in the classified supplement are available on Prestel (page 265) to any Prestel subscriber.

Authors who have any urgent matter to submit may send it by the editorial department's fax machine (01 383 6418). We welcome letters, obituaries, proof corrections, and any other copy sent by arrangement with an editor but do not want junk mail or full length manuscripts (which should be sent by a courier or wait until the post is working normally).

\section{Herstory of medicine}

Women rarely make it into traditional histories of medicine claims Lesley Hall in her introduction to the latest exhibition at the Wellcome Institute for the History of Medicine. These histories give occasional glimpses of women such as "the old woman of Shropshire," whose family receipt for the treatment of dropsy led William Withering to the discovery of digitalis, and Sarah Nelmes, the milkmaid whose hand Edward Jenner used to confirm his hypothesis about cowpox. Mostly, however, "women's role seems to consist chiefly of being the grateful-or victimised-patient."

Hygieia's Handmaids seeks to turn the limelight away from the heroic surgeon and pioneering physician to other aspects of caring for the sick and preserving health. There women have always been present. Sections of the exhibition are devoted to aspects of obvious concern to women-midwifery and child care-and also to women's participation in alternative medicine, philanthropy, and medical reform.

The exhibition charts women's struggle

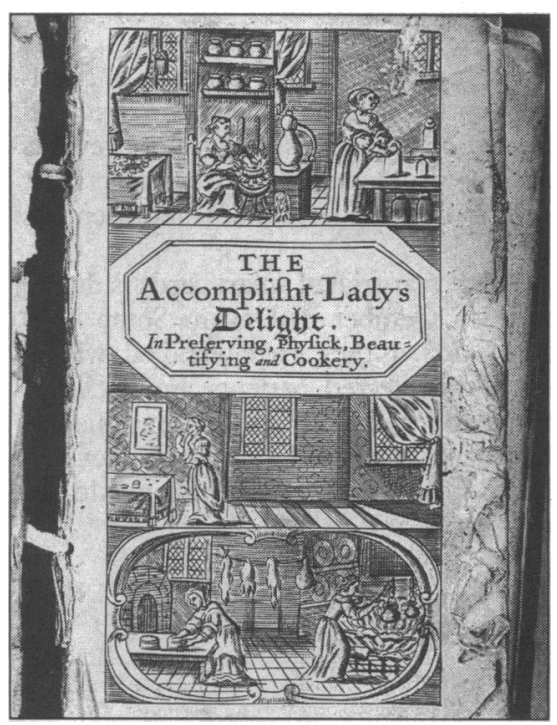

Doctor in the House (1675)

to become doctors, using an editorial from the $B M \mathcal{F}$ (2 April 1870) to give some idea of what the nineteenth century campaigners were up against.

Hygieia's Handmaids: Women, Health,

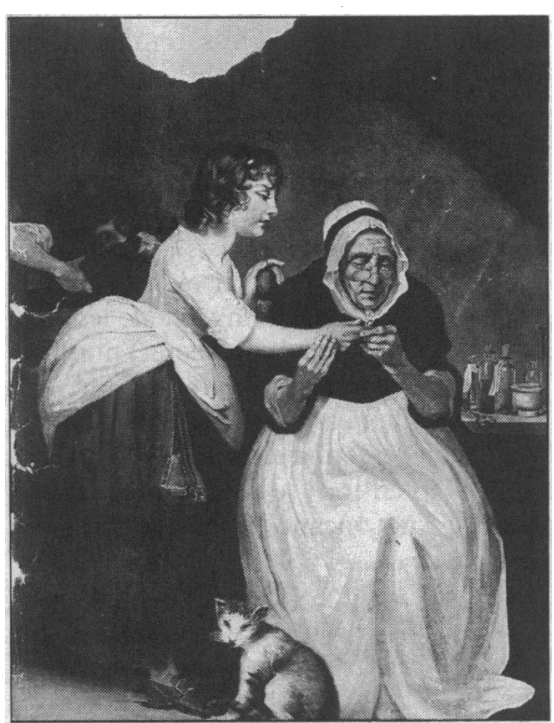

The Village Doctress (The cat at her feet may allude to the traditional connection between women healers and witchcraft)

and Healing continues at the Wellcome Institute for the History of Medicine, 183 Euston Road, London, Mondays to Fridays (945 am to $515 \mathrm{pm}$ ), until 16 December. 